Boise State University

ScholarWorks

$1-1-2007$

Office Nurse Educators: Improving Diabetes SelfManagement for the Latino Population in the Clinic Setting

Dawn Weiler

Boise State University

Laura Tirrell 


\title{
Office Nurse Educators: Improving Diabetes Self-Management for the Latino Population in the Clinic Setting
}

\author{
Dawn M. Weiler, MS, RN, ANP \\ Boise State University, ID \\ Laura Tirrell, MD, MHSA \\ Boise, ID
}

\begin{abstract}
Diabetes patients who understand their disease and how to manage it can achieve a lower complication rate. The American Diabetes Association recommends that patients receive self-management education and that patients' skills and knowledge be reassessed annually. The Healthy People 2010 objectives include a goal of at least $60 \%$ of diabetes patients receiving diabetes education. However, to date overall, far fewer (20\%-50\%) obtain comprehensive diabetes education and skills development to effectively implement self-management techniques. Low-income Latino patients generally fare even worse. This article describes a successful method to address this problem: the development and evaluation of an in-house diabetes education program, using office nurses.
\end{abstract}

\begin{abstract}
Está bien establecido que los pacientes diabéticos, que entienden su enfermedad, y como dirigirla o administrarla, pueden lograr un índice de complicación más bajo. La Asociación Americana de la Diabetes recomienda que los pacientes reciban educación de auto-administración, y que las habilidades y conocimiento de los pacientes se evalúen anualmente (cada año). Los objetivos de Healthy People 2010 (Gente Sana 2010, en español) incluye una meta de que por lo menos 60\% de los pacientes diabéticos reciban educación sobre la diabetes. Sin embargo, el total hasta la fecha, muchos menos (20-50\%) obtienen educación extensa sobre la diabetes y el desarrollo de las habilidades para eficazmente implementar técnicas de auto-administración. Generalmente a los pacientes Latinos de bajos ingresos les va todavía peor. Este artículo describe un método que tiene éxito para abocar este problema, por medio de desarrollar y evaluar un programa educativo en-la-casa sobre la diabetes, utilizando enfermeras de oficina.
\end{abstract}

Keywords: diabetes; self-management; Hispanic; diabetes education; primary care

$\mathrm{I}$ $\mathrm{t}$ is well established that motivated diabetes patients who understand their disease and how to manage it experience fewer complications (Diabetes Control and Complications Trial Research Group, 1993; UK Prospective Diabetes Study Group, 1998a, 1998b). The American Diabetes Association recommends that all diabetes patients receive self-management education and that those patients' skills and knowledge be reassessed annually (American Diabetes Association, 2003). Healthy People 2010 objectives list the goal of at least $60 \%$ of diabetes patients receiving diabetes education
(U.S. Department of Health and Human Services, 2000). In reality, only a fraction of diabetes patients $(20 \%-$ $50 \%)$ ever obtain comprehensive diabetes education and develop the skills to care effectively for themselves (Clement, 1995).

Many studies support diabetes education to help patients reach competency and motivation to effectively care for themselves (Clement, 1995). Unfortunately, these studies often fail to include a full description of the diabetes education intervention tested to allow replication in other settings, and some studies do not describe the 
demographic characteristics of the study population (Brown, 1999). Often, the specifics of which personnel actually provided the education, and methods for assessing their efficacy, have been omitted (Young-Hyman, 1999). Despite the fact that $76 \%$ of diabetes outpatient visits occur in primary care settings, few studies have described how to integrate diabetes education into this setting (Peterson \& Vinicor, 1998).

This paper will describe how a community health clinic developed an in-house diabetes education program using Latina office nurses. The low-income Latino patients achieved clinically important improvement in glycemic control.

\section{OfFice Nurse EducAtor Program Setting}

The diabetes nurse educator program was developed in a private, not-for-profit, federally designated "rural community health center" in southwest Idaho. The health center serves populations facing barriers to care, with emphasis on culturally sensitive care to migrant and seasonal farmworkers and the homeless. The clinic employs 18 primary care providers (10 physicians, 4 nurse practitioners, and 4 physician assistants), 3 pharmacists, 3 registered nurses, 7 licensed practical nurses and 11 medical assistants. The community clinic provides services 7 days a week, including evening clinics 5 nights a week, to approximately 21,000 patients ( $45 \%$ of whom are Hispanic).

\section{Nurse Educator Training Program}

Preliminary chart review found that low-income Latino patients often did not attend recommended off-site diabetes education sessions with Certified Diabetes Educators (CDE), with financial cost, language barrier, and transportation barriers the apparent stumbling blocks. Accordingly, an on-site diabetes education program was developed by first sending bilingual Latina office nurses (both RN and LPN) to area CDE-based classes being taught for newlydiagnosed type 2 diabetes patients. Tuition for this training in the essentials of diabetes self-management was paid through scholarships from the CDE programs, or funded by grants from the Idaho Diabetes Control Program. Tuition ranged from $\$ 300$ to $\$ 500$ per nurse. The education programs lasted from 1 (intense) to 6 weeks, depending on the nurses' schedules.

Follow-up nursing education included a 4-hour, CDEbased diabetes self-management course (every other year) in which nurse educators review and update their knowledge by living 3 days the way diabetes patients live. This experience is modeled after the Clinical Diabetes Management in Primary Care education program at the
Park Nicollet Health Services International Diabetes Center in St. Louis Park, Minnesota. Additionally, least 4 hours of nursing meetings at the clinic, annually, address diabetes patient care. Finally, a Baccalaureate-prepared RN with additional diabetes training, as well as numerous clinicians, are available to answer nurse educators' questions as they arise.

Once trained, the clinic integrated the nurse educators into diabetes care in several ways. All diabetes patient education was completed by the diabetes office nurse educators once the educators were trained. Patients saw the nurse educators at the time of regularly scheduled clinician appointments, during separately scheduled diabetes education appointments, or saw the educator as part of a multidisciplinary Diabetes Emphasis Clinic. The Diabetes Emphasis Clinics are held weekly and during this clinic visit the patients are examined, have their diabetes management evaluated by a primary care provider (physician, nurse practitioner, or physician assistant), have their medication regime reviewed by a pharmacist, meet with social services, and participate in group or individual diabetes education sessions with the office nurse educators. Patients are scheduled into the Diabetes Emphasis Clinics approximately every 6 months.

\section{Evaluation OF THE NURSE Educators' KNOWledge BASE AND Teaching SKills}

The performance of the office nurse educators was evaluated. Two evaluation tools were developed with the assistance of the Boise State University Department of Nursing and the Idaho Diabetes Control Program: a test of diabetes knowledge and an observational checklist of teaching skills. Both tools were reviewed and critiqued by the Diabetes Management Team at the clinic, and by nursing faculty from Boise State University, Boise, Idaho for content validity, clarity, accuracy, and appropriateness to clients and the educators being evaluated.

The Diabetes Educator Knowledge Test (Appendix A) was developed using the National Certified Diabetes Educator Exam content areas (American Association of Diabetes Educators, 2001). These content areas are: (a) diabetes disease process and treatment options; (b) nutritional management; (c) physical activity; (d) medications; (e) monitoring blood glucose and urine ketones to improve control; (f) preventing, detecting, and treating acute complications; (g) preventing, detecting, and treating chronic complications; (h) goal setting to promote health and problem solving for daily living; (i) integrating psychosocial adjustments into daily life; and (j) promoting preconception care and managing diabetes during pregnancy. The test consists of 28 multiplechoice questions. Questions were derived from several 
sources, including Life Skills Diabetes Education Center in Nampa, Idaho; Diabetes Education Society; and an expert from the Boise State University Department of Nursing.

The Observational Checklist of Instructional Skills (Appendix B) was adapted from the Boise State University Education Department's classroom observation record and Idaho State University's Education Department field experiences record. This tool focuses on the content areas of importance in diabetes self-care and on client characteristics. The observational tool assesses the following: client literacy level, learning style, and family involvement and support, as well as educator teaching methods and content covered.

\section{Outcome Measure}

The clinic examined one patient outcome measure: the clinically used level of glycosylated hemoglobin $\left(\mathrm{HgbA}_{1} \mathrm{C}\right)$. Twenty patients were identified (by retrospective chart review and computerized billing data from the clinic) who met criteria for inclusion in the clinic study: (a) patients who saw a diabetes nurse educator between January 1, 2002 and September 31, 2002; (b) self-pay at the highest clinic discount rate; (c) Hispanic ethnicity; (d) aged 30 to 65 years; and (e) $\mathrm{HgbA}_{1} \mathrm{C}$ results drawn within 3 months prior to the diabetes nurse educator visit and one drawn 3 or more months after the nurse educator visit. If more than one post-intervention $\mathrm{HgbA}_{1} \mathrm{C}$ result was available, the most recent as of March 31, 2003 was used. During the study period, each member of the sample population attended a mean of 2.75 (range $1-7, S D=1.5$ ) sessions with the diabetes office nurse educators. A total of 55 diabetes education sessions were delivered by the office nurse educators to the sample population.

\section{RESULTS}

\section{Nurse Educator Knowledge of Diabetes Content Areas}

The four nurse educators showed mastery of the basic content areas of the diabetes education curriculum. The mean test score of the office nurse diabetes educators was $96 \%$ (range 93\%-100\%). For comparison, licensed practical nurses working in the clinic $(n=6)$, who were not designated diabetes educators and did not attend the diabetes education courses, had a mean test score of $90 \%$ (range 75\%-96\%). Knowledge deficits for the nurse educators were concentrated in the content area of "promoting preconception care and managing diabetes during pregnancy," which was not surprising as the education sessions attended by the nurse educators focused little attention on this topic.

\section{Observation of Instructional Skills}

Evaluation utilizing the Observational Checklist of Instructional Skills of the four office nurse diabetes educators (10 sessions observed) showed a high degree of uniformity and quality in the style and content of teaching. A total of 20 activities were scored as either present or absent during the education observations. The 10 key educational elements were reviewed $93 \%$ of the time (range 90\%$96 \%$ ). Review of the patient's chart was observed $75 \%$ of the time (range $50 \%-100 \%$ ). The use of multiple teaching materials (flip charts, handouts, goal setting books) was achieved in $100 \%$ of sessions, as was the specified learning environment (private, appropriate noise and lighting levels, temperature, and space). Interpersonal skills (verbal/ nonverbal communication, enthusiasm, listening, and empathy) were also uniformly observed ( $100 \%$ of observations). The notable deficiencies at this development stage, however, were neglect of assessment of patients' readiness to learn (literacy, learning style, motivation), and absence of family members from all teaching sessions.

\section{Patient Outcome Measure}

The patients in the sample had a prior mean $\mathrm{HgbA}_{1} \mathrm{C}$ of 11.2 (range 7.6-14.0, $S D=1.83$ ) falling to a mean of 8.5 (range $5.5-13.2, S D=2.13$ ) after the nurse educator intervention. Using a paired samples $t$-test, this change was statistically significant $(p=0.001, t=3.713, d f=19$, $n=20$ ) despite the small sample size. If it proves to be sustained, a fall in $\mathrm{HgbA}_{1} \mathrm{C}$ of this magnitude would be expected to have an enormous impact in decreasing diabetes complications in this highly vulnerable population. In comparison, the change in mean $\mathrm{HgbA}_{1} \mathrm{C}$ of a similar patient sample, prior to the initiation of the diabetes office nurse educator program, was not statistically significant $(p=0.357, t=0.944, d f=19, n=20)$. HgbA $_{1} \mathrm{C}$ levels ranged from 6.5-13.2 (mean 9.2, $S D=1.7$ ) at initial evaluation and 6.5-14.0 (mean 8.9, $S D=1.8$ ) in follow-up.

\section{Discussion}

Diabetes office nurse educators can be trained at minimal cost to a clinical facility. Even without scholarship funding for the CDE education programs for the nursing staff, the financial outlay is significantly lower than that of formal CDE training. In addition, the enhanced nursing knowledge and improved client outcomes are well worth the expenditures incurred by the institution. By adding to the knowledge base nurses already possess with CDE-taught courses, meaningful diabetes education can be brought into the primary care setting, thus decreasing the barriers to much-needed education for the low-income Latino population. The advantage of bringing diabetes education into the clinic setting can be expected to be profound, especially for this vulnerable population. 
Although the diabetes knowledge, as assessed in this study, of the general office nurse staff and that of the diabetes nurse educators was not significantly different, it is probable that as the nurse educators gained new knowledge they shared this with their coworkers, not an unexpected occurrence in a collegial working environment. Remedial work to improve assessment of patient readiness to learn needs to be addressed. Efforts are under way, using a staff member prepared with a Master of Social Work as well as mental health expertise, to further educate the nurses regarding the elements of change theory and goalsetting techniques. The lack of family participation in the educational sessions was likely influenced by the fact that most adults in this low-income population must maintain employment. Family members literally can not afford to accompany the patient to the clinic during working hours. Night and/or weekend education sessions may help in this regard. An explicit invitation for family members to attend either when scheduling patient visits, or in the appointment reminder call, also deserves consideration.

The authors acknowledge that other variables, not controlled for, may have influenced the improvement in diabetes control for the study population. Clinicians may have expended more time and effort with these patients due to their poor level of disease control. The intervention group may also have been more ready to make changes. Future studies of the efficacy of these nurse educators will need to address these variables.

\section{CONCLUSION}

A successful solution to educating uninsured Latino patients in a busy primary practice is to create, from existing office nursing staff, a subset of diabetes nurse educators. This can be done at relatively little expense to the practice. Nurses can obtain training as part of their continuing education requirements or certified diabetes educators in the community may be willing to volunteer their time to train office nurses. Once nurses are trained, clinic managers can use the tests of knowledge and observational tools presented here to assess staff knowledge and performance. It is expected that the same improvements in glycemic control observed in this group will be observed in other practices.

\section{REFERENCES}

American Association of Diabetes Educators. (2001). A CORE curriculum for diabetes education: Diabetes education and program management (4th ed.). Chicago: American Association of Diabetes Educators.

American Diabetes Association. (2003). Standards of medical care for patients with diabetes mellitus. Diabetes Care 26(Suppl. 1), S33-50.

Brown, S. (1999). Interventions to promote diabetes self management: State of the science. Diabetes Educator, 25(Suppl. 6), 52-61.
Clement, S. (1995). Diabetes self-management education Diabetes Care, 18(12), 1204-1214.

Diabetes Control and Complications Trial Research Group. (1993). The effect of intensive treatment of diabetes on the development and progression of long-term complications in insulin dependent diabetes mellitus. New England Journal of Medicine, 329(10), 977-986.

Peterson, K. A., \& Vinicor, F. (1998). Strategies to improve diabetes care delivery. Journal of Family Practice, 47(Suppl. 5), S55-62.

UK Prospective Diabetes Study Group. (1998a). Intensive blood glucose control with sulphonylureas or insulin compared with conventional treatment and risk of complications in patients with type 2 diabetes. Lancet, 352(8), 837-853.

UK Prospective Diabetes Study Group. (1998b). Effects of intensive blood-glucose control with metformin on complications in overweight patients with type 2 diabetes. Lancet, 352(8), 854-865.

U.S. Department of Health and Human Services. (2000). Healthy People 2010 (2nd ed.). Washington, DC: U.S. Printing Office.

Young-Hyman, D. (1999). Provider impact in diabetes education: What we know, what we would like to know, paradigms for asking. Diabetes Educator, 25(Suppl. 6), 34-42.

Correspondence regarding this article should be directed to Dawn $M$. Weiler, MS, RN, ANP, Department of Nursing, Boise State University, Boise, ID 83725. E-mail: dweiler@boisestate.edu

\section{Appendix A}

\section{Diabetes Educator Knowledge Test}

1. When recommending infant feeding options to women with previous history of gestational diabetes, which of the following are true?
A. If the woman required insulin therapy, breast-feed her baby.
B. If the woman continues to have elevated BG levels and is diagnosed with type 2 diabetes, breast feeding her baby is recommended.
C. Breast-feeding mobilizes fat stores and can help in weight reduction.
D. If the infant is macrosomic, breast-feeding may increase the risk of obesity later in life.

2. Diabetes is caused by which of the following?
A. Consuming a lot of sugar
B. A decrease in the body's secretion of insulin
C. A decrease in the activity of insulin
D. Skipping meals
E. Both A and B
F. Both B and C

3. When a person has type 2 diabetes, the body...
A. Is not using insulin well.
B. Is not making any insulin.
C. Is rejecting insulin.
D. Is destroying insulin. 
4. Blood glucose before meals should be in which range?
A. $\quad 50-70 \mathrm{mg} / \mathrm{dl}$
B. $70-120 \mathrm{mg} / \mathrm{dl}$
C. $125-170 \mathrm{mg} / \mathrm{dl}$
D. $170-210 \mathrm{mg} / \mathrm{dl}$

5. Choose the answer that can have an effect on glucose control.
A. Daily stress
B. Eating habits
C. Exercise
D. All of the above

6. Which of the following is not a source of carbohydrates?
A. Milk products
B. Meats
C. Breads and grains
D. Fruits

7. Choose the answer that is highest in saturated fat.
A. Butter, marbled meats, cheese, and cream
B. Olive oil, avocados, butter
C. Canola oil, skim milk, cheese
D. Lard, peanut butter, and safflower oil

8. How does exercise normally affect blood sugar levels?
A. It increases the blood sugar levels.
B. It decreases the blood sugar levels.
C. It does not affect blood sugar levels.
D. You shouldn't exercise if you have diabetes.

9. The best method for testing sugar or glucose levels in the body is ...
A. Testing the urine.
B. Testing the blood.
C. Both A and B.
D. Basing blood sugar levels on how you feel.

10. Drinking unsweetened fruit juice will affect blood sugar levels by ...
A. Raising blood sugar levels.
B. Lowering blood sugar levels.
C. Having no effect on blood sugar levels.
D. None of the above.

11. A diabetes patient does blood glucose selfmonitoring because it is:
A. Essential for intensive therapy.
B. Needed to determine the right amount of medication.
C. Useful even if diabetes is controlled with diet and exercise.
D. All of the above.

12. How does infection affect blood sugar levels?
A. It raises blood sugar levels.
B. It lowers blood sugar levels.
C. It does not have any effect on blood sugar levels.

13. A glycosylated hemoglobin test $\left(\mathrm{HbA}_{1} \mathrm{c}\right)$ is used to measure the blood sugar levels during which time frame?
A. 1 week
B. 2-4 months
C. 24 hours
D. 1 year

14. The typical goal for a diabetes patient's glycosylated hemoglobin test is:
A. $8 \%-10 \%$
B. $3 \%$
C. $6 \%-7 \%$
D. $11 \%-15 \%$

15. True or false: When you have an illness, you should stop taking your diabetes medication.
A. True
B. False
C. It doesn't matter.

16. The purpose of insulin in the body is to:
A. Stimulate cells to take up sugar from the bloodstream.
B. Store the body's sugar in the bloodstream.
C. Make red blood cells.
D. None of the above.

17. Diabetes medication is used to ...
A. Lower the blood glucose level.
B. Increase the release of insulin.
C. Fight insulin resistance.
D. All of the above.
E. None of the above.

18. When you are traveling, you should keep your diabetes medications and supplies ...
A. Checked in your luggage.
B. Carried with you.
C. At home because of airport security.
D. A and B are appropriate answers.

19. Diabetes can increase your risk of developing which of the following?
A. Kidney, eye, and heart disease
B. Cancer and liver disease
C. Lung and skin disease
D. None of the above

20. The best way for a person with diabetes to care for his/her feet is to ...

A. Soak them for an hour once a day.

B. Buy shoes that are one size larger than needed.

C. Inspect them daily for cuts and abrasions.

D. All of the above.

21. If you get sick with the flu, you should ...
A. Stop taking insulin and all of your diabetes pills.
B. Stop drinking fluids. 

C. Test your blood sugar levels more often.
D. Do nothing; the flu does not affect blood sugar levels.

22. Which of the following is a common symptom of hypoglycemia?
A. Increased weakness
B. Sweating
C. Shakiness
D. Irritability
E. All of the above

23. A good food to treat low blood sugar is ...
A. One medium hotdog.
B. One regular chocolate candy bar.
C. One cup of skim milk.
D. Two ounces of cheese.

24. Working on small behavioral changes can ...
A. Reduce stress and help you control diabetes.
B. Make you crazy.
C. Adversely affect diabetes control.
D. None of the above.

25. True or false: Individuals diagnosed with diabetes have no control over the development of complications.
A. True
B. False

26. The most important person on the health care team of a diabetes patient is ...
A. The physician.
B. The diabetes educator.
C. The dietician.
D. The patient.

27. The best time for a diabetes patient to exercise is ...
A. Before meals.
B. After meals.
C. Exercise does not affect diabetes management.
D. Never.

28. A diabetes patient who is pregnant will require...
A. Close monitoring of blood glucose and adjustments in insulin use.
B. Double her normal amount of insulin.
C. No changes in insulin therapy.
D. None of the above.

\section{Appendix B}

\section{Observational Checklist of Instructional Skills}

\section{Assessment}

Did the nurse educator review the patient's chart beforehand? Yes No

Did the nurse educator ask the patient about his/her learning style? Yes No
Readiness to learn

Client's motivation to learn assessed: Yes No

Client's reading level assessed: Yes No

Did they check literacy of client? How? Yes No

Was the client's family involvement assessed? Yes No

Teaching/Lesson Plan

Is there an outline to guide teaching? Yes No

\section{Education Content}

Yes $=$ was covered

No = was not covered

$\mathrm{NA}=$ not applicable

1. Describing the diabetes disease process and treatment options: Yes No

2. Including appropriate nutritional management: Yes No

3. Including integrating physical activity into lifestyle: Yes No

4. Using medications, if applicable, for therapeutic effectiveness: Yes No

5. Monitoring BG, blood, or urine ketones when appropriate, and results to improve control: Yes No

6. Preventing, detecting, and treating acute complications: Yes No

7. Preventing (through risk reduction behavior), detecting, and treating chronic complications: Yes No

8. Goal setting to promote health, and problem solving for daily living: Yes No

9. Integrating psychosocial adjustments into daily life: Yes No

10. Promoting preconception care, managing diabetes mellitus during pregnancy, and gestational diabetes management: Yes No NA

\section{Learning Tools Used/Learning Environment \\ Instructional learning materials used (videos, pam- phlets, verbal): Yes No (describe) \\ Privacy/noise level/lighting/temperature/space (writ- ing area): Yes No}

\section{Characteristics and Interpersonal Skills of Diabetes}

Educator (respond to each area)

Verbal/ nonverbal communication

Enthusiasm for teaching

Listens to clients/sensitive to signs of distress or problems

Demonstrates patience/empathy and understanding for client needs 